soldier who added it to his already over-weighted haversack.

"Adult Education in H.M. Forces"' suggests that the book is mainly concerned with a description of the educational scheme which has been developed in all three Services. This is not so. It has been designed particularly for the use of regimental instructors. On the other hand, Major Phillips and Capt. Curtis are much too modest in stating that the book would be useful only for unit education instructors. It would be of considerable value to all men and women in H.M. Forces whose duty it is to train other men and women in the use of weapons, the principles of wireless, the precautions to take against gas attacks or any other duty which involves the use of the instructional method. This point is admirably summed up in the preface by Brigadier C. G. Maude, controller of the Army Educational Corps, in his remark that "it is now no longer enough for an instructor to 'know his stuff', he must be able to 'put it across' in a clear and interesting manner".

The introductory chapter contains a brief account of the development of education in the Army. For the instructor the well-written chapter on "How People Learn" should be of great value. Here the authors emphasize the point that the real aim of the instructor is to stimulate others to learn, and not merely to impart knowledge. This brings out the important point that instruction is an active process for both speaker and listener.

Other sections of the book deal with the manner in which a talk might be prepared, the use of visual aids and the methods of guiding discussions. One or two examples to illustrate teaching method are included as well as some useful hints on how to handle adult classes. The book will be warmly welcomed by many Service men and women who, for the first time, have been called upon to instruct others.

"The Story of the British Army". By Dr. S. J. Curtis. Pp. 48. (Leeds : E. J. Arnold and Son, Ltd., 1943.) 18. $6 d$. net.

: "Adult Education in H.M. Fórces". By Major J. O. R. Phillips and

Dr. S. J. Curtis. Pp. 68. (Leeds: E. J. Arnold \& Son, Ltd., 1943.)

28. net.

\section{TESTING AND RATING AIR FILTERS}

$\mathrm{E}^{\mathrm{a}}$ QUIPMENT for securing data on the efficiencies of air filters is described in an article by $\mathrm{O}$. C. Eliason (Bell Lab. Rec., 21, No. 8 ; April, 1943). The laboratory test for measuring the capability of a filter consists in passing air containing a known concentration of a standard dust through the filter and measuring the amount of dust remaining in the air. The equipment includes a wind tunnel with a variable speed blower for controlling the volume of air, and there are pitot tubes and gauges for measuring the flow and the static pressure of the air in the turinel.

A machine has been developed for feeding dust into the air stream in the tunnel at a constant rate. A chain carries the dust from a hopper and drops it into an aspirator tube, from which it is blown into the air stream of the wind tunnel. A moving arm in the hopper stirs the dust and also wipes across the chain to ensure that it carries a uniform load. A standard dust, consisting of a mixture of lamp-black, powdered charcoal, iron oxide and wood flour, was chosen after considerable experimentation. It contains those components of natural dust which are most likely to tax the ability of air filters where dust conditions are severe.

An air sampling instrument for use in the field or in the laboratory was developed as a relatively accurate and easy means of determining, by weight, the amount of dust in the atmosphere and at the same time, by a discoloration test, affording a visual indication of the amount and character of the dust. It consists of a cylindrical chamber with one end screened and provided with a pipe, equipped with a pitot tube for measuring air flow, which connects the chamber with the suction side of a blower. To obtain a sample of the dust in the air, a white filter paper is placed over the screen and air is drawn through it at a constant rate. The dust in the air is deposited on the paper and its amount is quantitatively the difference in the weight of the paper before and after the test. The visual indication is given by the discoloration of the white filter paper.

The air filter on test is installed in the end of the wind tunnel and the volume of air through it is adjusted to its rated value. The dust feeder is then started, the volume of air and the rate of dust feed being constant throughout the test. Samples for determining efficiency are taken during the first hour and at specified intervals thereafter. Efficiency of dust removal is expressed as a ratio of the dust removed compared with the dust in the air entering the filter.

From the weight of dust fed during the test and the volume of air delivered by the blower, the amount of dust in grams per cubic foot of air entering the filter can be calculated. The corresponding amount of dust in the air leaving the filter can be calculated from the weight of that collected on the filter paper and from the volume of air passed through the filter paper. The filter paper is weighed before and after test on a balance sensitive to a tenth of a milligram, in a room in which temperature and relative humidity are constant. When tests are to be made outside the laboratory on air filters installed in a ventilating system two samplers are usəd, one on the intake side of the filter and the other on the outlet side. The efficiency of the filter is calculated from the difference in the weight of dust collected on the two filter papers.

\section{A NEW ORDER OF CRUSTACEA*}

$T$ $\mathrm{HE}$ minute crustacean which is the subject of this paper is a very interesting discovery. Derocheilocaris typicus n.g., n.sp., was found on the intertidal beaches and is regarded by the authors, probably justifiably, as belonging to a new order, which they name Mystacocarida. Although obviously closely allied to the Copepoda, it differs fundamentally in certain respects and is highly specialized in some ways and very primitive in others. The body consists, as in the Copepoda, of sixteen somites, of which the last six are legless. The somite of the maxillipede (first thoracic somite) is completely separated from the head-a most unusual feature. The last six * Mystacocarida. A New Order of Crustacea from Intertidal Beaches
in Massachusetts and Connecticut, by Robert W. Pennak and Donald J. Zinn. (Smithsonian Miscellaneous Collection. Vol. 103. No. 9. Smithsonian Institution, Washington, Publication 3704. 1943.) 